\title{
A INSERÇÃO DA TEMÁTICA SUSTENTABILIDADE EM UM PROGRAMA PRIVADO STRICTO SENSU EM ADMINISTRAÇÃO: O ISOMORFISMO INSTITUCIONAL COMO POTENCIALIZADOR DA MUDANÇA ORGANIZACIONAL

\author{
THE INSERTION OF SUSTAINABILITY IN A PRIVATE \\ STRICTO SENSU PROGRAM IN ADMINISTRATION: INSTITUTIONAL \\ ISOMORPHISM AS A POTENTIATOR OF CHANGE
}

Carlos Eduardo de Lima
Mestre em Administração (Universidade Estadual
de Londrina/Brasil). Professor na Unicesumar
(Maringá/Brasil). E-mail: delima@uel.br.
Saulo Fabianono Amâncio-Vieira
Doutor em Administração (Universidade Nove de
Julho/Brasil). Professorn na Universidade Estadual
de Londrina (Londrina/Brasil). E-mail: saulo@uel.br.

\section{Dayane Freire Romagnolo}

Mestra em Administração (Universidade Estadual de

Londrina/ Brasil). Professora na Universidade Norte do

Paraná (Guarapuava/Brasil).E-mail: romagnolo@uel.br.

de Londrina (Londrina/Brasil).E-mail: saulo@uel.br. 


\section{RESUMO}

O presente trabalho buscou analisar a internalização da temática da sustentabilidade no currículo do Programa de Pós-Graduação em Administração de Empresas da Universidade de Fortaleza - PPGA-UNIFOR. O aporte teórico do estudo contemplou os três tipos de Isomorfismo Institucional (mimético, normativo e coercitivo) bem como a educação para sustentabilidade. O percurso metodológico escolhido tem como principais características: a pesquisa qualitativa baseada em estudo de caso único e composto de dados primários e secundários. Para análise, foi utilizada análise de conteúdo, baseada nas categorias oriundas do isomorfismo institucional. Entre os resultados, evidenciou-se que a presença de alguns pesquisadores de sustentabilidade já existentes no PPGA-UNIFOR e a chegada de professores e pesquisadores, advindos de outras instituições, foram determinantes para a consolidação do projeto de se inserir a temática da sustentabilidade no referido Programa. Na perspectiva institucional, essa "parceria" foi fruto de dois mecanismos: o isomorfismo mimético e isomorfismo normativo. O mimético manifestou-se pelo fato do PPGA-UNIFOR buscar em uma instituição já consolidada no campo os elementos para compor suas práticas. O normativo, por sua vez, destacou-se pela constituição de uma rede de profissionais que, por sua formação universitária pregressa, possuíam habilidades e competências de ocupar posições estratégicas na organização. Pode-se considerar que a relação estabelecida entre as duas instituições não foi pontual e persistiu ao longo de alguns anos.

Palavras-chave: Sustentabilidade. Administração. Isomorfismo institucional. Stricto Sensu.

\section{ABSTRACT}

The present work sought to analyze the internalization of sustainability in the curriculum of the Postgraduate Program in Business Administration of the University of Fortaleza - PPGA-UNIFOR. Theoretical contribution contemplated the three types of Institutional Isomorphism (mimetic, normative and coercive) as well as education for sustainability and Administration. The methodological path chosen has as main characteristics: the qualitative research based on a single case study and through primary and secondary data. For the analysis, categories from the institutional isomorphism were used. Among the results, it was evidenced that the presence of some sustainability researchers already existing in the PPGA-UNIFOR and the arrival of professors and researchers, coming from other institutions, were decisive for the consolidation of the project to insert the sustainability theme in said Program. In the institutional perspective, this "partnership" was the result of two mechanisms: the mimetic isomorphism and normative isomorphism. The mimetic manifested itself in the fact that the PPGA-UNIFOR sought in an institution already consolidated in the field the elements to compose its practices. The normative, in turn, was distinguished by the constitution of a network of professionals who, through their previous university education, had the skills and competences to occupy strategic positions in the organization. It can be considered that the relationship established between the two institutions was not punctual and persisted over a few years.

Keywords: Sustainability. Administration. Institutional isomorphism. Stricto Sensu. 


\section{INTRODUÇÃO}

Existe um crescente interesse nos estudos organizacionais e da gestão em abordar a importância da sustentabilidade no contexto empresarial contemporâneo (ALLEN; CUNLIFFE; EASTERBY-SMITH, 2016). Este fato é evidenciado no número de cursos, periódicos especiais e artigos que exploram temas relacionados, por exemplo, à gestão para sustentabilidade, mudanças do comportamento do consumidor, produção mais limpa, mudança climática e inovação social (STARIK; KANASHIRO, 2013; FERNANDES; LIMA; AMÂNCIO-VIEIRA, 2015; WRIGHT et al., 2013).

Mais recentemente, a sustentabilidade tem chamado atenção também nas escolas de negócios, devido a necessidade de formação de um perfil de profissional capaz de tomar decisões que envolvam motivações além das dimensões econômicas, típicas do mainstream. Para Allen, Cunliffe e Easterby-Smith (2016), esta característica emerge devido a necessidade de se examinar as responsabilidades dos gestores e acadêmicos em contribuir para o desenvolvimento sustentável e encontrar maneiras de envolver proativamente as organizações para assumirem a responsabilidade pela promoção do bem-estar dos ecossistemas e das comunidades.

Na área de Administração, em nível nacional, a inserção da sustentabilidade nos currículos e seus desdobramentos têm sido discutida, principalmente em nível de graduação, como é possível destacar nos trabalhos de Palma, Oliveira e Viacava (2011), Palma e Silva (2012), Brunstein, Scartezini e Rodrigues (2012), Silva, Campanário e Souza (2013), Gonçalves-Dias, Herrera e Souza (2013), Palma e Pedroso (2014), Dangelo e Brunstein (2014), Matos et al. (2014), Melo, Brunstein e Godoy (2014), Welzel (2014) e Brunstein et al., (2015).

Nota-se que há uma lacuna em compreender como os cursos de pós-graduação de nível stricto sensu em Administração têm aderido estas discussões e implementado a educação para sustentabilidade em seus currículos e práticas. A pesquisa de Lima (2016) destacou que, no ano de 2015, entre os mais de cem programas de pós-graduação em Administração no Brasil, apenas quatro deles possuíam linhas de pesquisa e área de concentração voltadas à sustentabilidade e que entre estes, havia apenas um único programa privado que contemplava a temática nas duas esferas: o Programa de Pós-Graduação em Administração de Empresas da Universidade de Fortaleza (PPGA-UNIFOR).

Diante desta especificidade, o objetivo deste trabalho é analisar como ocorreu a inserção da temática sustentabilidade no PPGA-UNIFOR. Cabe destacar que as diretrizes legais para a inserção de temáticas socioambientais não são bem definidas para o nível stricto sensu e que para os demais níveis, elas ressaltam o papel da educação ambiental. Salienta-se ainda o fato de que a Administração, por natureza, se demonstra como uma das áreas mais difíceis de introduzir a temática da sustentabilidade (SPRINGETT, 2010). Entre 
as dificuldades, é possível citar aquelas que são intrínsecas da própria área: pensamento linear, divisão do conhecimento, abordagem de ensino baseado em estudo de caso e com pouca visão de longo prazo (JACOBI; RAUFFLET; ARRUDA, 2011). O que tornou, ao longo dos anos, a educação na área de Administração simplificada em uma visão pragmática e determinista (PALMA; SILVA, 2012).

Como perspectiva teórica para análise do fenômeno, tem-se a Teoria Institucional. Os teóricos desta vertente geralmente escolhem uma problemática que envolve as explicações sobre por que se adota um conjunto específico de formas, procedimentos ou símbolos institucionais, com particular atenção à difusão dessas práticas (HALL; TAYLOR, 2003; MEYER; ROWAN, 2006). Além disso, Greenwood, Jennings e Hinings (2015) afirmam que esse tipo de análise consegue conectar com o nível macro da análise ligado à sustentabilidade. Ademais, Greenwood e Hinings (1996) e Suddaby e Viale (2015) destacam que a teoria institucional tem uma contribuição para entender a mudança organizacional, que vai além das ideias de inércia e persistência.

Pretende-se, portanto, mais do que descrever a adesão da temática, demonstrar os fatores que contribuíram para a introdução e manutenção das questões relacionadas à sustentabilidade no currículo do PPGAUNIFOR. Para tanto, o trabalho foi organizado da seguinte forma: inicialmente há o desenvolvimento do quadro teórico, posteriormente apresenta-se os aspectos metodológicos e a forma de análise empregada, seguida das considerações finais.

\section{APORTE TEÓRICO}

Nesta seção são expostos os dois marcos teóricos do trabalho: o primeiro aborda a teoria institucional e isomorfismo; o segundo retrata a educação para sustentabilidade na Administração.

\subsection{TEORIA INSTITUCIONAL E ISOMORFISMO}

A perspectiva institucional tem sido considerada uma das mais férteis teorias para análise dos fenômenos organizacionais. Baseada nas contribuições clássicas de Max Weber, Émile Durkheim e Karl Marx, a tradição institucionalista demarca a importância de se compreender como o comportamento está imerso em um contexto mais amplo de relações históricas e estruturas sociais coletivas (SCOTT, 2014). A teoria, ao explicar como ocorrem as mudanças organizacionais, tem dado ênfase especial ao ambiente em que a organização atua e a forma em que estas ações organizacionais são conectadas com este ambiente (SLACK; HININGS, 1994).

Neste aspecto, DiMaggio e Powell (1983) argumentam que a difusão do modelo burocrático, por exemplo, ocorreu devido ao processo de isomorfismo. Para os autores, esse é o melhor meio de descrever a semelhança 
entre as organizações de um determinado campo. DiMaggio e Powell (1983) afirmam que o isomorfismo é dividido em: i) competitivo, em que predomina a ideia da ecologia populacional, presumindo a racionalidade sistêmica que enfatiza a competição de mercado, a mudança de nicho, medidas de ajustamento; e ii) o institucional que se refere aos mecanismos de isomorfismo mimético, coercitivo e normativo.

O isomorfismo mimético é adotado a partir de ambientes de incerteza, quando organizações tomam outras como modelo de atuação. Dessa forma, as organizações acabam servindo como fonte de práticas de sucesso para outras de seu campo. Comumente, organizações novas tomam como modelo as com maior tempo de experiência e com práticas já difundidas, desenvolvidas e legitimadas (DIMAGGIO; POWELL, 1983).

O isomorfismo coercitivo contempla os resultados das pressões formais e informais, em que organizações são submetidas por outras organizações dependentes e por características ligadas à cultura da sociedade em que a organização atua. Outra questão relacionada ao mecanismo que influenciam na estrutura e no comportamento das organizações é a existência de um ambiente legal (DIMAGGIO; POWELL, 1983). Neste sentido, Hoffman (2001) argumentou que a criação e a adoção de novas práticas ambientais por setoreschave da indústria química juntamente a sanções do governo (leis, regulamentos e punições) têm sido fundamentais para o surgimento de novas lógicas de gestão ambiental nos Estados Unidos.

Para DiMaggio e Powell (1983), o terceiro tipo de isomorfismo, o normativo, basicamente é derivado da profissionalização presente nas organizações. Os campos organizacionais que possuem a utilização de força de trabalho profissional são orientados por esse tipo de isomorfismo devido à própria natureza do negócio, que traz homogeneização de linguagem, procedimentos, formas de atuação etc.

Tendo em vista que a sustentabilidade passou a fazer parte da estrutura curricular, dos projetos e grupos de pesquisas na instituição abordada neste estudo e, mesmo que o PPGA- UNIFOR possua suas especificidades, o isomorfismo é um elemento relevante para a constituição analítica deste trabalho. Nesse aspecto, compartilha-se do exposto por Machado-da-Silva e Gonçalves (1999), cuja afirmação é de que os mecanismos que pressionam em direção ao isomorfismo são fundamentais para o entendimento da dinâmica de mudança.

\subsection{EDUCAÇÃO, SUSTENTABILIDADE E ADMINISTRAÇÃO}

O termo sustentabilidade tem sua origem nas ciências naturais (Ecologia e Biologia) e no decorrer dos anos passou a fazer parte de outras áreas do conhecimento. Atualmente, tem sido um elemento central no chamado desenvolvimento sustentável e está relacionado a melhoria na qualidade de vida humana, 
concomitante com a minimização das externalidades negativas oriundas das ações antrópicas sobre o meio ambiente. O caráter ambiental, que the era característico inicialmente, foi acrescido de novas dimensões, entre elas a social, econômica, cultural e política (OSORIO; LOBATO; CASTILHO 2005; SEGHEZZO 2009).

Mesmo sendo alvo de críticas e tendo alto nível de complexidade, no que tange o seu entendimento, definição e prática, a sustentabilidade socioambiental e o desenvolvimento sustentável emergiram como propostas de equilíbrio entre as ações antrópicas, as peculiaridades dos ecossistemas e a busca por equidade social entre os seres humanos. Desde então, um intenso debate vem ocorrendo entre os acadêmicos, consultores e executivos de empresas, resultando em muitas definições de uma forma mais humana, mais ética e transparente de fazer negócios (VAN MARREWIJK, 2003).

Perrow (1997) argumenta que as organizações têm sido o ator causador da maior alteração no meio natural. Ao mesmo tempo, o autor destaca que as possíveis soluções para essas questões podem ser originadas nas próprias organizações. Diante do exposto e fazendo um comparativo com as organizações atuais, notase que é necessário empreender mudança e rompimento com determinadas premissas prevalecentes na sociedade. Hoffman (2001) afirma que a mudança organizacional envolve desaprender o que tem sido enraizado ao longo da história da organização.

A mudança sugerida, muitas vezes, se refletirá em resistência. Neste aspecto, ressalta-se que o desafio da sustentabilidade não é apenas um problema para gestão e implementação de políticas eficazes. Conforme apontam Malheiros et al. (2013), é um desafio e um convite para o desenvolvimento de conhecimento integrado, de base interdisciplinar e intercultural. Os autores também chamam a atenção para a necessidade de investigação que motive a ação, o desenvolvimento tecnológico e processos de educação nas instituições de ensino e principalmente nas universidades.

Dessa forma, Malheiros et al., (2013) afirmam que as instituições de educação superior já não são mais vistas somente como fonte única de conhecimento disciplinar e formação de profissionais que integrarão a sociedade e contribuirão para o seu progresso econômico. Mas, sim, também como um dos importantes atores para oferecer projetos sustentáveis, tendo como fator central a educação como ferramenta indutora de mudanças positivas de caráter coletivo e que estimulem a sua emancipação. Ainda segundo os autores, universidades têm papel fundamental no sucesso dessas políticas de sustentabilidade e são atores-chave, junto de atores políticos e econômicos.

Evidencia-se que a universidade, como uma organização, possui características que vão além da formação profissional e intelectual. No momento em que as demandas da sociedade estão ligadas à novos anseios, 
entre eles os da sustentabilidade, estas instituições necessitam responder tais demandas mediante seu tripé de atuação: ensino, pesquisa e extensão. Este movimento já é notado em pesquisas nacionais e internacionais, perpassando várias áreas do conhecimento, entre elas o campo da administração.

Todavia, Springett (2010) e Godoy, Brunstein e Fischer (2013) advertem que enquanto esta discussão soa familiar em áreas como a Sociologia, Filosofia e nas Ciências Biológicas, nas escolas de Administração as discussões desta natureza ainda repercutem de forma estranha. Entre as explicações, está o fato de existir a tendência dos setores de serviços em seguir o mundo corporativo em valores e objetivos voltados para o mercado e concomitante relutância por parte de muitos acadêmicos da escola de negócios para o conhecimento fora da ortodoxia convencional da área (SPRINGETT; KEARINS, 2001).

Considerando a trajetória evolutiva das escolas de Administração, Beusch (2014) afirma que, até 1940, o foco das escolas de negócio recaía sobre a racionalidade gerencial e o objetivo do ensino naquele período era criar valor através da utilização eficiente de recursos. Ainda segundo o autor, no período posterior, entre 1950 e 1990, as racionalidades predominantes foram gerenciais e de mercado. Apenas na primeira década do terceiro milênio que a gestão e a educação empresarial passaram a incorporar uma racionalidade mais voltada para sociedade, baseada em atender às suas necessidades de longo prazo, promovendo dentre outras práticas o uso sustentável dos recursos naturais.

O estudo de Figueiró e Raufflet (2015) evidenciou que internacionalmente, enquanto campo de conhecimento, a sustentabilidade na educação gerencial demonstra-se fragmentada em termos de diversidade de questões, metodologias, estruturas teóricas ou abordagens, e propostas de pesquisas.

Em nível nacional, Venske e Nascimento (2013) afirmam que a educação para a sustentabilidade na área de administração necessita de marcos conceituais plurais, que orientem a reorganização institucional necessária para tornar possível a inserção de questões socioambientais. Os autores destacam que é importante considerar que a finalidade da administração deve ir além dos limites organizacionais, pois necessita estar comprometida também com a melhoria das condições humanas.

\section{PERCURSO METOdOLÓGICO}

O presente estudo analisa como ocorreu a inserção da temática da sustentabilidade no PPGA-UNIFOR. A pesquisa foi conduzida seguindo pressupostos da abordagem qualitativa e exploratória. A estratégia é baseada em estudo de caso único e descritivo (STAKE, 2005), considerando que foram expostas sequências de fatos e ações ao longo do tempo. A seleção do caso considerou que o programa em questão é o único de 
natureza privada a ter direcionado sua área de concentração e uma das linhas de pesquisa para a temática da sustentabilidade, sendo também o único no Nordeste do país a ter esta característica.

A pesquisa utilizou-se de dados secundários, cujas fontes são documentos oficiais emitidos pela Coordenação de Aperfeiçoamento de Pessoal de Nível Superior (CAPES) (relatórios, descrição do programa, dados de avaliação, proposta do programa, relação de disciplinas) e do próprio PPGA-UNIFOR (história, descrição do curso, grade curricular, teses e dissertações); diário de campo, pois parte da pesquisa foi realizada na instituição, na cidade de Fortaleza, e dados primários coletados mediante roteiro de entrevista semiestruturado.

As entrevistas, em profundidade, foram direcionadas àqueles indivíduos que atuam ou atuaram no curso como docentes e/ou pesquisadores, mas também estiveram presentes nele no período em que a sustentabilidade ainda não era um tema em pauta. O intuito dessa seleção foi contemplar a trajetória da inserção da temática, possibilitando comparar os estágios da institucionalização. Neste aspecto, a estratégia de estudo de caso corrobora com os pressupostos de Berger e Luckmann (2010) ao concluírem que a realidade é socialmente construída e, dessa forma, envolve a participação direta dos sujeitos tanto pela linguagem, quanto pelas práticas. Os entrevistados foram classificados como E1, E2 e E3 e cada entrevista durou, em média, uma hora e quinze minutos.

A análise dos dados foi conduzida mediante análise de conteúdo, obedecendo aos pressupostos de categorização presentes em Bardin (2009). A técnica para análise segue o que a autora caracteriza como temática, pois buscou-se mediante as categorias presentes nos dados (documentos e entrevistas) a presença de significação atrelada ao objetivo do trabalho. As categorias orientadoras, com base em DiMaggio e Powell (1983), são:

a. Isomorfismo mimético: as organizações tomam outras organizações como modelo de atuação, servindo como uma fonte de práticas que uma organização pode se utilizar, que outras organizações já utilizam com sucesso. Usualmente, organizações novas tomam como modelo as organizações com maior tempo de experiência e com práticas já difundidas e desenvolvidas no mercado;

b. Isomorfismo coercitivo: é o resultado de pressões formais tanto quanto informais em que as organizações são submetidas por outras organizações dependentes ou pelas características culturais da sociedade em que a organização está inserida. Outra forma importante nesta categoria é a existência de um ambiente legal, que afeta aspectos do comportamento e da estrutura das organizações; 
c. Isomorfismo normativo: é uma derivação da profissionalização das organizações; campos organizacionais que têm a utilização de força de trabalho profissional são orientados por esse tipo de isomorfismo devido ao próprio tipo do negócio que traz padronizações, como em linguagem, procedimentos, forma de atuação etc.

As categorias foram estabelecidas previamente, desse modo, foi possível sistematizar e guiar a exploração realizada no campo. Na sequência, são apresentados os resultados da pesquisa.

\section{RESULTADOS DA PESQUISA}

Nesta seção do trabalho são discutidos os resultados da pesquisa e os principais desdobramentos da análise.

\subsection{ANTECEDENTES DA INSTITUCIONALIZAÇÃO}

Quando se avalia a trajetória do curso do PPGA-UNIFOR, nota-se que sua concepção se orientava para temas tradicionais na área de Administração. Esta afirmação é perceptível em sua descrição, no ano de 1998, três anos após sua criação.

O Curso de Mestrado em Administração da UNIFOR teve sua criação em 1995 motivada para preencher lacuna existente no Ceará no que se refere à capacitação de pesquisadores, professores executivos e consultores na Ciência da Administração [...] é um Curso de Pós-Graduação Stricto Sensu que visa a preparação de recursos humanos de alto nível, através de atividades integradas de ensino e pesquisa interdisciplinares, para o exercício profissional e acadêmico na área de Administração Geral [...]. Sua visão estratégica é estar sempre à frente da base científica e práticas administrativas da região e ser lócus de referência no campo da Ciência Administrativa. Sua missão é contribuir para evolução da pesquisa científica, da cultura estratégica e organizacional e das práticas da Ciência Administrativa nas Organizações do Estado do Ceará (CAPES, 1998b, p. 2).

Não apenas a adesão à temática na área de concentração e na linha de pesquisa, em 2010, foi a responsável pela instituição inserir a sustentabilidade em seu currículo e práticas. Desde o ano de 2002, já se discutia uma dimensão da temática em uma disciplina de nome Gestão Ambiental, com a seguinte ementa:

Gestão ambiental: conceitos, origem, principais correntes. Histórico e condicionantes culturais. Gestão ambiental e a teoria das organizações. Legislação ambiental. Normas. Sistemas de gestão ambiental. Gestão ambiental no Brasil. Gestão ambiental no Ceará (CAPES, 2002, p. 7). 
Para Leal-Filho (2015), quando se analisa a inserção da sustentabilidade nas organizações, as questões ambientais representam as discussões iniciais. Outro indicativo de que a temática já era discutida e pesquisada no programa mesmo antes das alterações em uma das linhas de pesquisa e área de concentração está presente no número de dissertações e teses defendidas ao longo dos anos, conforme Figura 1.

Figura 1 - Dissertações e teses que abordam temas tradicionais na área de Administração e Sustentabilidade, entre 1997 e 2016

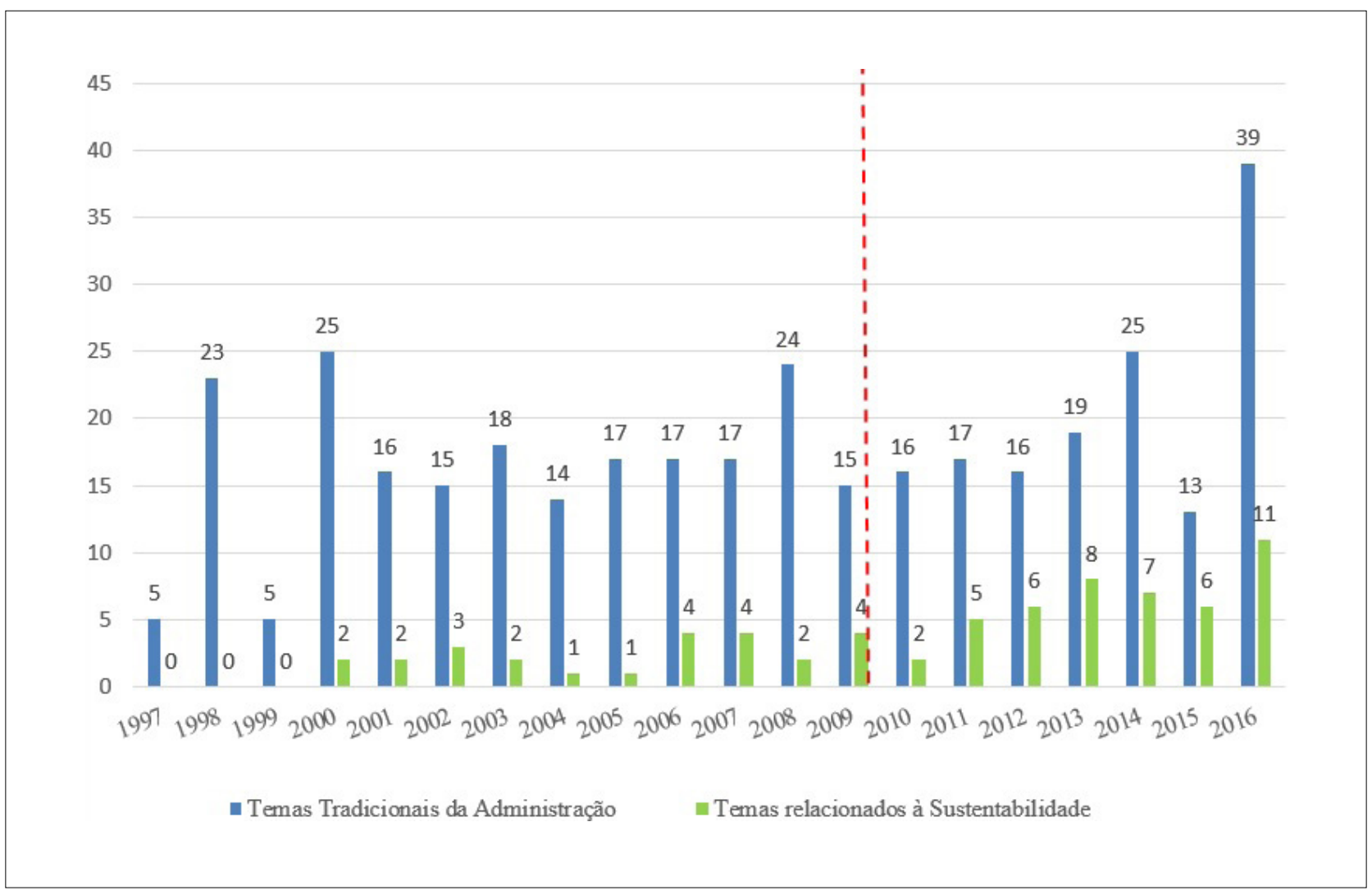

Fonte: Elaborado pelos autores com base em PPGA-UNIFOR (2017)

Desde o ano 2000, já existiam trabalhos que abordavam a temática da sustentabilidade. Essa característica se deve ao fato de existirem no programa pesquisadores com formação no exterior, onde tiveram contato com a temática e essa experiência se refletia nas disciplinas ministradas, orientações de trabalhos e nas pesquisas 
desenvolvidas. Entre os entrevistados, dois compunham este grupo de pesquisadores. Mediante pesquisa na Plataforma Lattes, verificou-se que ambos realizaram suas pesquisas de doutorado abordando questões relacionadas à sustentabilidade ou ao desenvolvimento sustentável. O E1 fez o doutorado em Economia na Universidade de New Hampshire, nos Estados Unidos; assim como o E2, com doutorado em Economia na Universidade Paris XIII, na França. Quando questionados sobre suas formações e experiências de pesquisa, os informantes deram os seguintes relatos:

E1. Sim, existe uma relação direta entre a minha formação especificamente e com os estudos que eu fiz em sustentabilidade e desenvolvimento sustentável no meu doutorado e a minha atual condição como professor. Sou professor de linha específica da área e escrevo artigos também sobre o assunto. Tudo vinculado com a área da minha formação [...] desenvolvimento endógeno [...] que passava também pelo desenvolvimento sustentável.

E2. E o doutorado veio depois que entrei na UFC, na Universidade Federal, e no doutorado eu foquei na questão ambiente [...] na incorporação da variável ambiental na avaliação econômica de projetos. Na década de 1990, eu tive a oportunidade de fazer disciplinas com o professor René Passet, Ignacy Sachs e a professora Syhlvie Faucheux, em Paris.

E2. Interessante porque esta experiência que tive na França me deu oportunidade de estender para outros projetos que eu fiz com a África, em Moçambique, um estudo que engloba a questão da sustentabilidade, sobre a contribuição para a cadeia da pesca em Moçambique, fiz com financiamento do Banco Mundial.

Para Scott (2003), indivíduos com essas características de formação agem como "veículos institucionais" ao longo do tempo e no espaço. Os pesquisadores com conhecimento prévio em questões da sustentabilidade, como os mencionados nos dados da pesquisa, atuam a partir de: sistemas relacionais, que consistem em ligações tanto interpessoais quanto interorganizacionais; e as rotinas (comportamento habitualizado) manifestadas por meio de ações padronizadas que refletem o conhecimento tácito realizado e transmitido por atores organizacionais (SCOTT, 2003). Desse modo, agem como intermediários da instituição e atuam como "participantes ativos na formação e reconstrução de ideias a serem transmitidas" (SCOTT, 2003, p. 888).

Ao longo de sete anos, a disciplina Gestão Ambiental era a única que contemplava alguma dimensão da sustentabilidade no programa. Outras inclusões de disciplinas ocorreram no ano de 2008 quando a Responsabilidade Social Corporativa e Governança e Sustainable Development Strategies passaram a ser ofertadas no curso, sendo a última ministrada por um dos dois docentes recém-contratados pela instituição, oriundos do Programa de Pós-Graduação em Administração da Universidade Federal do Rio Grande do Sul (PPGA-UFRGS). 


\section{Gestãoe Desenvolvimento}

Em 2009, o número de disciplinas que abordavam a temática continuou sendo três, esse ano também era o último com as antigas linhas de pesquisa e área de concentração. A transformação das linhas e da área de concentração e a evolução curricular do PPGA-UNIFOR, ao longo dos anos de 2000, estão ilustradas na Figura 2.

Figura 2 - Disciplinas ofertadas pelo PPGA-UNIFOR em 2002, 2008, 2009 e 2010

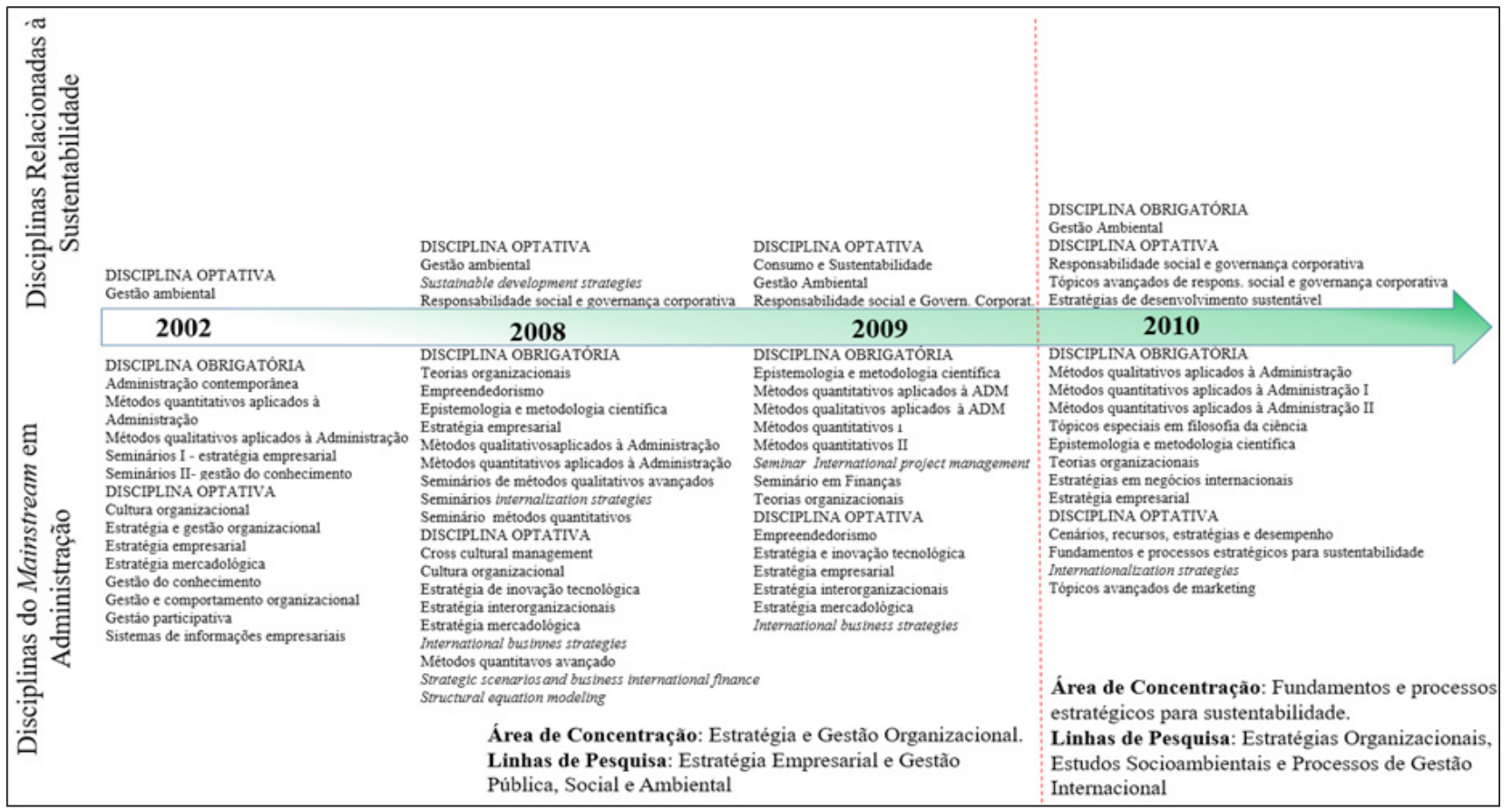

Fonte: Elaborado pelos autores (2017) com base em CAPES (2002; 2008; 2009; 2010)

Em 2010, houve um redirecionamento do Programa, procurando dar maior peso às questões de sustentabilidade. Para este fim, foram implementadas as seguintes ações: i) mudança no nome da área de concentração, de Estratégia e Gestão Organizacional, tornou-se Fundamentos e Processos Estratégicos para a Sustentabilidade; ii) o número de disciplinas que abordam a temática passou a ser quatro; iii) a disciplina Gestão Ambiental passou a ser obrigatória; e iv) as linhas de pesquisa passaram a ser três: Estratégias Organizacionais, Estudos Socioambientais e Processos de Gestão Internacionais. 


\section{Gestãoe \\ Desenvolvimento}

Tais mudanças indicam que a temática da sustentabilidade emergia em direção a um status mais permanente e disseminado no programa. Por meio destas ações, o PPGA-UNIFOR passou a ter o primeiro curso de doutorado em Administração do estado e implantou um dos primeiros programas do país a ter área de concentração e linha de pesquisa com foco em questões socioambientais.

Como resultado deste processo, a sustentabilidade ganhou maior espaço no programa, sendo este contemplado por sua missão:

Contribuir para a evolução da pesquisa científica, da cultura estratégica e organizacional em prol do desenvolvimento sustentável e da sustentabilidade, considerando as especificidades dos mais variados tipos de organizações, do Estado do Ceará, da região Nordeste, do Brasil (CAPES, 2010, p. 6).

Van Marrewijk (2003) discorre que a perspectiva filosófica por trás da sustentabilidade nas organizações revela que as circunstâncias sociais mudam, convidando a organização a responder e, consequentemente, a repensar seu papel na sociedade. Assim, elas tendem a realinhar todas as suas instituições (tais como missão, visão, implantação de políticas, tomada de decisões, comunicação, assuntos corporativos etc.).

Para Greenwood e Hinings (2002), a difusão de uma nova instituição só ocorrerá se as novas práticas forem vistas como mais adequadas do que as antigas, tornando-se objetivadas; revestindo-se de valor no consenso social e se difundindo mais amplamente. Nota-se que, após a mudança de área de concentração no PPGAUNIFOR, em 2010, os currículos dos anos de 2011, 2012 e 2015 demonstram um movimento de inclusão de novas disciplinas focadas na temática, o que indica sua difusão. Esta evolução encontra-se demonstrada na Figura 3. 


\section{Gestãoe Desenvolvimento}

Figura 3 - Disciplinas ofertadas pelo PPGA-UNIFOR em 2011, 2012 e 2015

\begin{tabular}{|c|c|c|c|}
\hline 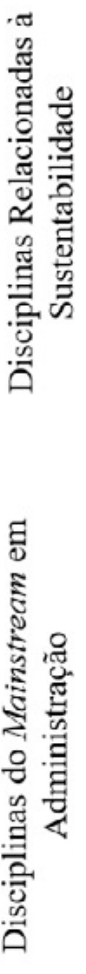 & 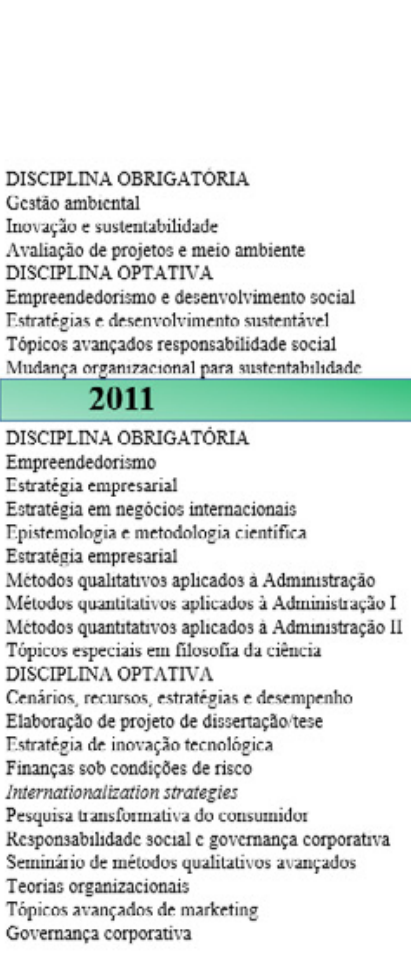 & 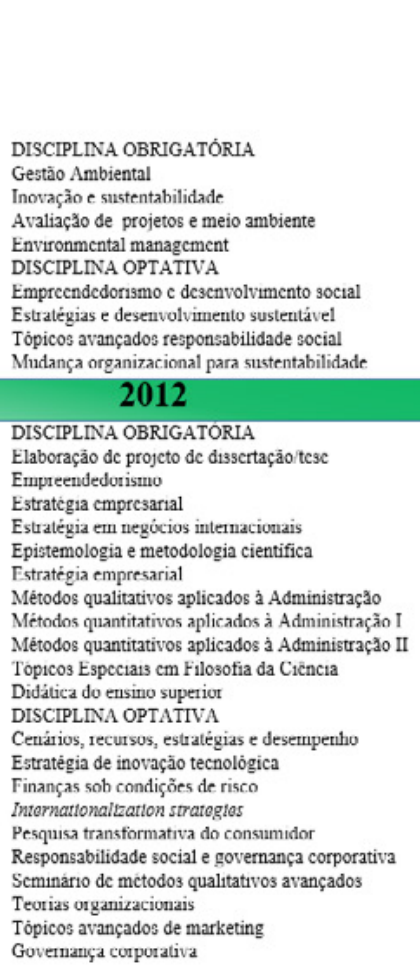 & 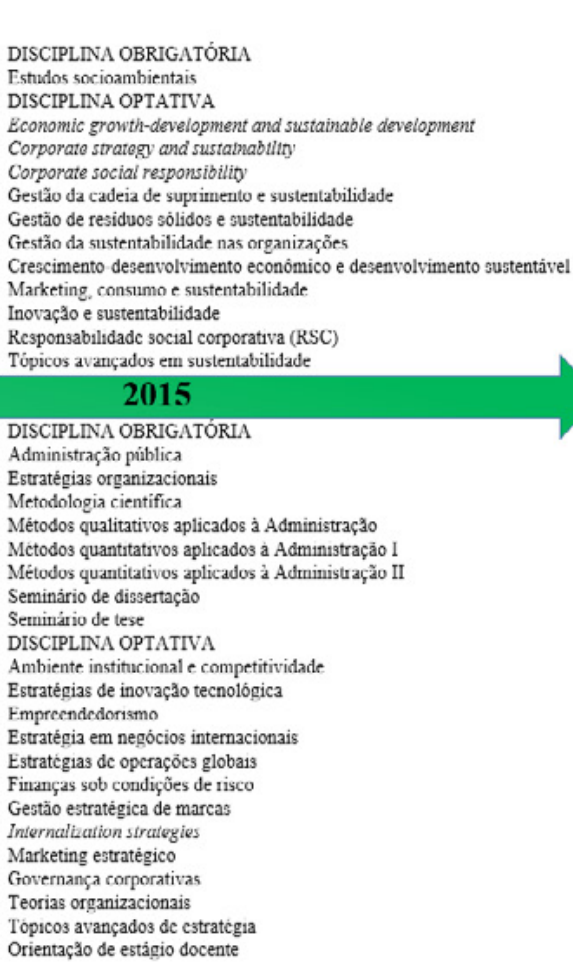 \\
\hline
\end{tabular}

Fonte: Elaborado pelos autores (2017) com base em CAPES (2011; 2012; 2015)

Nos referidos anos, a sustentabilidade ganhou mais espaço e representatividade no programa. Em 2011 e 2012, três disciplinas com foco na temática eram obrigatórias e quatro, optativas. No ano de 2015, o número de disciplinas obrigatórias foi reduzido para uma e o número de optativas ampliado para onze. Como consequência da abertura do curso de doutorado, as primeiras teses foram defendidas, cinco das quais, em 2015, abordavam a temática da sustentabilidade.

\subsection{ISOMORFISMO E A INSTITUCIONALIZAÇÃO DA SUSTENTABILIDADE NO PPGA-UNIFOR}

Na relação do PPGA-UNIFOR com o campo organizacional, destacou-se sua aproximação com o PPGAUFRGS. Com a contratação de dois professores no período anterior ao da mudança da área de concentração, 
iniciava-se um processo de isomorfismo entre as instituições. Quando questionados sobre as instituições que influenciaram na adesão da sustentabilidade do programa, os relatos foram os seguintes:

E1. Sim, foi feito esse tipo de pesquisa, principalmente pela participação de outros professores que eram fortes pesquisadores, fortes cientistas da área de sustentabilidade. Inclusive, dois professores da Universidade Federal do Rio Grande do Sul. [...]. De instituição: escola de Administração da UFRGS, do PPGA de lá, com o professor (NOME) e a (NOME) também e alguns outros professores que eu não me recordo atualmente.

E2. O (NOME) e o E3, os dois professores muito inseridos nessas questões de estudos de sustentabilidade, juntamente com outros professores que a gente tinha no programa e que ainda tem hoje.

E3. Era interessante o fato de se fazer a parceria com um programa mais consolidado, daí eu acho que algumas disciplinas foram dadas por professores de outras instituições. Eu acho que o professor (NOME) e o (NOME) do PPGA-UFRGS foram dar alguma disciplina.

Estes fragmentos demonstram o isomorfismo mimético, tido como aquele no qual as organizações recorrem às outras ao tentarem minimizar suas incertezas, especialmente quando seus objetivos são ambíguos e se procura legitimá-los imitando-se uma organização de destaque no campo (DIMAGGIO; POWELL, 1983); no caso, o PPGA-UFRGS. O fragmento de E3 cita o nome de professores do PPGA-UFRGS e a necessidade de buscar uma instituição já consolidada no campo. Geralmente essa busca ocorre em momento de mudança e incerteza. Essa incerteza faz que as organizações tenham mais predisposição para a imitação, uma vez que, as organizações se espelham em organizações que tenham a aparência de mais legítimas e/ou de bemsucedidas (DIMAGGIO; POWELL, 1991).

A representatividade do PPGA-UFRGS no campo foi evidenciada em Fernandes, Lima e Amâncio-Vieira (2015), que destacaram o fato da instituição ser a segunda com maior influência em número de publicações em sustentabilidade em periódicos de alto impacto no país, no campo da Administração. Ainda, ser elemento central na rede de comunicação científica na área de sustentabilidade e ter dois pesquisadores entre os mais produtivos no campo nacional.

Essa aproximação institucional não foi momentânea e envolveu a contratação por parte do PPGA-UNIFOR, tanto de egressos do programa de doutorado do PPGA-UFRGS, quanto de professores do PPGA-UFRGS, como evidencia-se no documento em que a instituição expõe sua evolução e tendências, no ano de 2011: 
Intercâmbios institucionais envolvendo atividades de docência e pesquisa: Professores de diferentes instituições locais, de outros estados e também de diferentes países participaram, em 2011, de atividades acadêmicas no PPGA. Tem sido comum a prática do PPGA em ofertar seminários como parte da grade de oferta dos semestres. Em 2010, o seminário "Gestão Socioambiental nos Setores Público, Privado e Não-Governamental", com carga horária de 15 horas, foi ministrado pelo Prof. Luiz Felipe do Nascimento, da Universidade Federal do Rio Grande do Sul UFRGS (CAPES, 2011, p. 10).

E a previsão da parceria para o futuro:

Como fruto das sinergias do Projeto PROCAD, em 2010, professores da UFRGS participaram de várias bancas de defesa de dissertação do PPGA. Além disso, um exaluno de mestrado do PPGA que participou de estágio sanduíche de mestrado na UFRGS é atualmente aluno de doutorado dessa instituição coordenadora do Projeto FUNCAP. O cronograma das atividades futuras do projeto está estabelecido na versão já aprovada pela CAPES (2011-2013), e estão previstos intercâmbios de professores e alunos entre as instituições para os anos de 2011, 2012 e 2013 (CAPES, 2011, p. 11).

Em 2012, o próprio programa considerava a questão da parceria um ponto forte da instituição:

É de fundamental importância para a melhora qualitativa do PPGA-UNIFOR o estímulo à integração com outros programas de ponta no Brasil na Área de Administração. Assim, é vital contar com a participação de professores colaboradores de importantes IES brasileiras e do exterior. Nessa direção, 4 professores (dois da Escola de Administração de Empresas da Universidade Federal do Rio Grande do Sul - Prof. Eugênio Pedrozo e Prof. Felipe Nascimento[...] já fazem parte do quadro de colaboradores do programa. A integração deles com os professores do PPGA-UNIFOR é de grande importância, em virtude de suas expertises em publicações em periódicos internacionais de impacto, suas experiências em orientação de alunos de doutorado, e do fato de possibilitar a participação dos professores do PPGA em bancas de defesa de teses de doutorado, que precisamos melhorar (CAPES, 2012, p. 12).

Ainda, por meio da pesquisa constatou-se que dois professores contratados, no ano de 2015, para o quadro docente do programa eram alunos egressos do PPGA-UFRGS. Assim, denota-se que essa relação não ficou isolada em determinado período, mas tem sido uma estratégia da organização. Entre as explicações para esta aproximação, tem-se o relato de E3, ex-aluno do PPGA-UFRGS e contratado como docente no PPGA-UNIFOR. 
E3. O que acabou acontecendo é que, me contrataram e eu trabalhava com isso (com a sustentabilidade). Então se abriu a oportunidade de se fazer algo nessa área [...] a gente passou a contratar outras pessoas, mas estavam relacionadas com meu círculo, pessoas que eu conhecia e eram também pessoas que estavam de alguma forma na área [...] acabou sendo também pessoas da área.

Para Díez-de-Castro, Díez-Martín e Vázquez-Sanchéz (2015), participações em redes sociais criam convergência de atitudes e comportamentos. Aqueles que realizam atividades sociais tendem a se congraçar com outras organizações similares, fomentando relações que podem ser muito estáveis e de confiança mútua proporcionando o compartilhamento de valores comuns. Nesse aspecto, a rede de relacionamentos de um egresso do PPGA-UFRGS facilitou que outros docentes, membros de sua antiga escola e também pesquisadores na área de sustentabilidade fossem trabalhar no PPGA-UNIFOR.

O que foi relatado por E3 também explicita a presença de isomorfismo normativo que, segundo DiMaggio e Powell (1983), advém da educação formal e da legitimação em uma base cognitiva produzida por especialistas universitários. O segundo aspecto também presente é o crescimento e a constituição de redes profissionais que permeiam as organizações. Tais mecanismos criam um grupo de indivíduos quase intercambiáveis que ocupam posições semelhantes numa ampla gama de organizações. Ainda nessa perspectiva, tem-se que as universidades se constituem em "importantes centros de desenvolvimento de normas para o comportamento organizacional entre os profissionais, gerentes, administradores e seus colaboradores” (DIMAGGIO; POWELL, 1983, p. 80).

Outro importante mecanismo estimulador do isomorfismo normativo destacado por DiMaggio e Powell (1983) e presente no fragmento, é a seleção de pessoal. Dentro de diversos campos organizacionais, a seleção faz-se por contratação de indivíduos de empresas do mesmo ramo e de pessoal de um grupo restrito de instituições de treinamento, faz-se também pela promoção de práticas comuns. No caso, a prática comum refere-se ao conhecimento prévio em sustentabilidade, propiciado por uma instituição que ocupe posição central no campo.

Não foi detectado na pesquisa a presença de isomorfismo coercitivo, deduz-se aqui que a ausência de marcos legais e diretrizes específicas da temática para o nível de pós-graduação stricto sensu, faz com que não haja respostas da instituição e, dessa forma, não afetam sua estrutura e comportamento.

\section{5 À GUISA DE CONCLUSÃo}

A educação para sustentabilidade pode ser responsável pela formação de um novo tipo de profissional, capaz de refletir de forma mais complexa sobre as decisões ao incorporar novas dimensões (ambiental, social, 
cultural e territorial) e, dessa forma, influenciar os processos de decisão nas organizações. Desse modo, esta discussão também necessita estar presente no nível stricto sensu, haja vista o perfil de pesquisa e formação docente atrelados a este nível de ensino no Brasil.

Neste sentido, este trabalho buscou analisar como ocorreu a inserção da temática da sustentabilidade no PPGA-UNIFOR. Para compreender este fenômeno, empreendeu-se uma pesquisa qualitativa baseada em estudo de caso único mediante dados primários e secundários. Para análise, foram utilizadas categorias oriundas do Neoinstitucionalismo Sociológico, mais precisamente no que se refere ao isomorfismo institucional.

A educação para sustentabilidade teve sua primeira incursão mediante a disciplina de Gestão Ambiental, porém ao longo dos anos, novas surgiram com características que contemplavam outras dimensões da sustentabilidade. Entre os resultados, evidenciou-se que a presença de alguns pesquisadores de sustentabilidade já existentes no Programa e a chegada de professores e pesquisadores, tanto doutores egressos como pesquisadores consolidados na área, advindos de outras instituições, foram determinantes para a consolidação do projeto de se inserir a temática da sustentabilidade no PPGA-UNIFOR.

Na perspectiva institucional, essa "parceria" foi fruto de dois mecanismos: o isomorfismo mimético e isomorfismo normativo. O mimético se destacou pelo fato do PPGA-UNIFOR buscar em uma instituição já consolidada no campo os elementos para compor suas práticas, no caso o PPGA-UFGRS. Entre as ações, destacaram-se as parcerias entre alunos, professores e também projetos de pesquisa. No isomorfismo normativo, tem-se a constituição de uma rede de profissionais que, por sua formação universitária pregressa, possuía habilidades e competências de ocupar posições estratégicas na organização, como ensinar e pesquisar sobre sustentabilidade e seus desdobramentos. Pode-se considerar que a relação estabelecida entre as duas instituições não foi pontual e persistiu ao longo de alguns anos.

Para pesquisas futuras, sugere-se que outros programas de pós-graduação, e até outros níveis de ensino, possam ser estudados a fim de comparar o processo de inserção de temas relacionados à sustentabilidade. Outras evidências, como a trajetória dos grupos e projetos de pesquisa, e a comunicação científica produzida por esses programas podem ser utilizados na análise. 


\section{REFERÊNCIAS}

ALLEN, S.; CUNLIFFE, A. L.; EASTERBY-SMITH, M. Understanding Sustainability Through the Lens of Ecocentric Radical-Reflexivity: Implications for Management Education. Journal of Business Ethics, v. 139, n. 4, dez. 2016.

BARDIN, L. Análise de conteúdo. 4. ed. Lisboa: Edições 70, 2009.

BERGER, P. L.; LUCKMANN, T. A Construção social da realidade. 32. ed. Petrópolis: Vozes, 2010.

BEUSCH, P. Towards sustainable capitalism in the development of higher education business school curricula and management, International Journal of Educational Management, v. 28, p. 523- 545. 2014.

BRUNSTEIN, J.; JAIME, P. ; CURI, D. P. ; D’ANGELO, M. J.; MAINARDES, E. W. Assessment and evaluation of higher education in business management: an analysis of the Brazilian case in the light of social learning theory for sustainability. Assessment \& Evaluation in Higher Education, v. 1, p. 1-22, 2015.

BRUNSTEIN, J.; SCARTEZINI, V. N.; RODRIGUES, A. L. Sustentabilidade na educação corporativa e o desenvolvimento de competências societais. Organizações \& Sociedade, v. 19, 2012.

CAMPBELL, J. L. Institutional change and globalization. Princeton, NJ: Princeton University Press. 2004.

CAPES - COMISSÃO DE APERFEIÇOAMENTO DE PESSOAL DE NÍVEL. Cadernos de Avaliação. Descrição do Programa. 1998b. Disponível em: <http://conteudoweb.capes.gov.br/conteudoweb/CadernoAvaliacaoServlet?cadernosavaliacao=Enviar>. Acesso em: 12 fev. 2017.

Cadernos de Avaliação. Disciplinas. 2002. Disponível em: <http://conteudoweb.capes.gov.br/conteudoweb/CadernoAvaliacaoServlet?cadernosavaliacao=Enviar>. Acesso em: 20 fev. 2017.

Cadernos de Avaliação. Disciplinas. 2008. Disponível em: < http://conteudoweb.capes.gov.br/conteudoweb/CadernoAvaliacaoServlet?cadernosavaliacao=Enviar>. Acesso em: 20 fev. 2017.

Cadernos de Avaliação. Disciplinas. 2009. Disponível em: < http://conteudoweb.capes.gov.br/conteudoweb/CadernoAvaliacaoServlet?cadernosavaliacao=Enviar>. Acesso em: 20 fev. 2017.

Cadernos de Avaliação. Disciplinas. 2010. Disponível em: < http://conteudoweb.capes.gov.br/conteudoweb/CadernoAvaliacaoServlet?cadernosavaliacao=Enviar>. Acesso em: 20 fev. 2017. 
Cadernos de Avaliação. Disciplinas. 2011. Disponível em: < http://conteudoweb.capes.gov.br/conteudoweb/CadernoAvaliacaoServlet?cadernosavaliacao=Enviar>. Acesso em: 20 fev. 2017.

Cadernos de Avaliação. Disciplinas. 2012. Disponível em: < http://conteudoweb.capes.gov.br/conteudoweb/CadernoAvaliacaoServlet?cadernosavaliacao=Enviar>. Acesso em: 20 fev. 2017.

Cadernos de Avaliação. Descrição do Programa. 2012. Disponível em: < http://conteudoweb.capes.gov.br/conteudoweb/CadernoAvaliacaoServlet?cadernosavaliacao=Enviar>. Acesso em: 20 fev. 2017.

Cadernos de Avaliação. Descrição do Programa. 2015. Disponível em: < http://conteudoweb.capes.gov.br/conteudoweb/CadernoAvaliacaoServlet?cadernosavaliacao=Enviar>. Acesso em: 20 fev. 2017.

D’ANGELO, M. J.; BRUNSTEIN, J. Social learning for sustainability: supporting sustainable business in Brazil regarding multiple social actors, relationships and interests. International Journal of Sustainable Development and World Ecology, v. 21, p. 273-289, 2014.

DÍEZ-DE-CASTRO, E.; DÍEZ-MARTÍN, F.; VÁZQUEZ-SÁNCHEZ, A. Antecedentes de la institucionalización de las organizaciones. Cuadernos de Gestión, n. 1, v. 15, p. 15-38, 2015.

DIMAGGIO, P. J., POWELL, W. W. The iron cage revisited: institutional isomorphism and collective rationality in organizational fields. American Sociological Review, v. 48, 1983.

. Introduction. In: Zucker, Lynne G. (Org.). Institutional patterns and organizations: culture and environment. The new institucionalism in organizational analysis. Chicago: The University of Chicago press, 1991, p. 1-38.

FERNANDES, É. Á.; DE LIMA, C. E. AMÂNCIO-VIEIRA, S.F. O desenvolvimento da pesquisa científica no Brasil envolvendo organizações e sustentabilidade: evolução e estruturação do campo na área de administração. In: Anais... II Encontro Latino Americano de Universidades Sustentáveis. Porto Alegre, 2015.

FIGUEIRÓ, P. S.; RAUFFLET, E. Sustainability in higher education: a systematic review with focus on management education, Journal of Cleaner Production, v. 106, p. 22-33, nov. 2015.

GODOY, A.S.; BRUNSTEIN, J.; FISCHER, T. M. D. Introdução ao Fórum Temático Sustentabilidade nas Escolas de Administração: tensões e desafios. RAM, v. 14, 2013.

GONÇALVES-DIAS, S. L. F.; HERRERA, C. B.; SOUZA, C. M. T. Desafios (e dilemas) para inserir 'sustentabilidade' nos currículos de administração: um estudo de caso. Revista de Administração Mackenzie, v. 14, p. 119-153, 2013. 
GREENWOOD, R.; HININGS, C. R Understanding radical organizational change: bringing together the old and the new institutionalism. Academy of Management Review, v. 21, n. 4, p. 1022-1054, 1996.

GREENWOOD, R.; JENNINGS, P. D.; HININGS, B. Sustainability and organizational change. In: HENDERSON, R.; GULATI, R.; TUSHMAN, M. Leading sustainable change: an organizational perspective. Oxford: Oxford University Press, p. 323-355, 2015.

GREENWOOD, R.; OLIVER, C.; SUDDABY, R.; SAHLIN, K. (Org.). The Sage Handbook of Organizational Institutionalism. London: Sage, 2008.

HALL, P. A.; TAYLOR, C. R. As três versões do neo-institucionalismo. Lua Nova, São Paulo, n. 58, 2003.

HOFFMAN, A. J. From heresy to dogma: an institutional history of corporate environmentalism. Stanford: Stanford University Press, 2001

JACOBI, P. R.; RAUFFLET, A. E.; ARRUDA, M. de. Educação para a sustentabilidade nos cursos de Administração: reflexão sobre paradigmas e práticas. RAM, São Paulo, v. 12, n. 3, jun. 2011.

LAWRENCE, T. B.; SUDDABY, R. Institutions and institutional work. In: CLEGG, S; HARDY, C.; LAWRENCE. T. B.; NORD, W. R. (Org.), Handbook of Organization Studies. 2. ed. p. 215-254. London: Sage. 2006.

LEAL-FILHO, W. Education for Sustainable Development in Higher Education: Reviewing Needs. In: LEAL-FILHO, W. (Org.). Transformative Approaches to Sustainable Development at Universities. Hamburg: Springer. 2015.

LIMA, C. E. A Institucionalização da Temática Sustentabilidade em Pós-Graduações Stricto Sensu em Administração no Brasil. 181 p. Dissertação (Mestrado em Administração) - Universidade Estadual de Londrina, Londrina, 2016.

LIMA, C. E. AMÂNCIOVIEIRA, S. F. A Institucionalização da Temática da Sustentabilidade no Programa de PósGraduação em Administração da Universidade Estadual de Londrina. Anais... XL ENANPAD, Costa do Sauípe BA. 2016.

MACHADO-DA-SILVA, C. L.; GONÇALVES, S. A. Nota Técnica: a teoria institucional. In: CLEGG, S. et al. Handbook de Estudos Organizacionais. São Paulo: Atlas, 1999.

MATOS, F. R. N. et al. Representações sociais e sustentabilidade: o significado do termo para alunos do curso de administração. In: BRUNSTEIN, J.; GODOY, A. S.; SILVA, H. C. (Org.). Educação para a sustentabilidade nas escolas de administração. 1. ed. São Carlos: RIMA, 2014. 
MELO, E. C.; BRUNSTEIN, J.; GODOY, A. S. Experiências docentes de educação para sustentabilidade na sala de aula de administração. Pretexto, Belo Horizonte. v. 15, 2014.

MEYER, H. D.; ROWAN, B. Institutional Analysis and the Study of Education. In: (Org.). The New Insti-

tutionalism in Education. State University of New York Press: Albany, 2006.

OSORIO, L. A. R.; LOBATO, M. O.; CASTILLO, X. A. Debates on sustainable development: towards a holistic view of reality. Environment, Development and Sustainability, v.7, p. 501-518, 2005.

PALMA, L. C.; OLIVEIRA, L.; VIACAVA, K. R. Sustainability in brazilian federal universities. International Journal of Sustainability in Higher Education, v. 12, p. 250-258, 2011.

PALMA, L. C.; SILVA, D. R. Sustainability as an integration proposal for teaching: a study of the pedagogical projects of the management courses at the Federal Institute of Education, Science and Technology of Rio Grande do Sul (IFRS). In: LEAL FILHO, W. (Org.). Sustainable Development at Universities: New Horizons. 1ed. Frankfurt: Peter Lang Scientific Publishers, 2012.

PALMA, L. C.; PEDROZO, E. A. A Complex Framework: Expanding the Understanding of the Human Being and Organizations to Integrate Sustainability in Education and Promote Transformative Learning. In: LEAL FILHO, W.; BRANDLI, L.; KUZNETSOVA, O; DO PAÇO, A. M. F. (Org.). Integrative Approaches to Sustainable Development at University Level. Suiça: Springer International Publishing, 2014.

PPGA-UNIFOR. Programa de Pós-Graduação em Administração da Universidade de Fortaleza. Disponível em: <http://www.unifor.br/index.php?option=com_content\&view=article\&id=423\&ltemid=881>. Acesso em: 23 fev. 2017.

SCOTT, W. R. Institutional carriers: reviewing modes of transporting ideas over time and space and considering their consequences. Industrial and Corporate Change, v. 12, n. 4, p. 879-894. 2003.

Institution and organizations: ideas, interests, and identities. 4. ed. Thousand Oaks, CA. Thousand Oaks: Sage Publications, 2014.

SEGHEZZO, L. The five dimensions of sustainability. Environmental Politics, n. 18, v. 4, 539-556, 2009.

SILVA, H. H. M.; CAMPANÁRIO, M. A.; SOUZA, M. T. S. O isomorfismo na educação ambiental como tema transversal em programas de graduação em administração. Revista de Ciências da Administração, v. 15, p. 170-186, 2013. 
SLACK, T.; HININGS, B. Institutional pressures and isomorphic change: an empirical test. Organization Studies, v. 15, n. 6, p. 803-827, 1994.

SPRINGETT, D. Education for Sustainability in Business Studies Curriculum. In: JONES, P. ; SELBY, D., STERLING, S. (Org.). Sustainability Education: perspectives and practices across high education, London: Earthscan. 2010.

STAKE, R. E. Qualitative case studies. In: DENZIN, N. K.; LINCOLN, Y. S. Handbook of Qualitative Research. 3. ed. Thousand Oaks: Sage Publications, p. 443-466. 2005.

STARIK, M.; KANASHIRO, P. Toward a Theory of Sustainability Management Uncovering and Integrating the Nearly Obvious. Organization and Environment, v. 26, n. 7, 2013.

VAN MARREWIJK, M. Concepts and Definitions of CSR and Corporate Sustainability: Between Agency and Communion. Journal of Business Ethics, v. 44, n. 2-3, p. 95-105, 2003.

VENZKE, C. S.; NASCIMENTO, L. F. M. Caminhos e desafios para a inserção da sustentabilidade socioambiental na formação do administrador brasileiro. Revista de Administração do Mackenzie, v. 14, 2013.

WRIGHT, C.; NYBERG, D.; DE COCK, C.; WHITEMAN, G. Future imaginings: organizing in response to climate change. Organization, v. 20, n. 5, p. 647-658, 2013.

WELZEL, E. Afinal, quem são os gestores da responsabilidade social corporativa (RSC)? Implicações para a formação dos administradores. In: BRUNSTEIN; GODOY; SILVA. (Org.). Educação para a sustentabilidade nas escolas de administração. São Carlos, SP: RIMA Editora, v. 1, 2014. 